\title{
Analisis Kinerja PLTD Dual-Fuel Di PT. Indonesia Power UBP Bali
}

\section{Gede Kusuma Putra ${ }^{1)^{\star}}$, I Gusti Bagus Wijaya Kusuma ${ }^{2)}$, I Made Dwi Budiana Penindra ${ }^{2)}$}

\author{
1)Jurusan Teknik Mesin, Fakultas Teknik, Universitas Udayana \\ Kampus Bukit Jimbaran, Badung, Bali, Indonesia 80361 \\ Email: kputra431@gmail.com, igbwijayakusuma@unud.ac.id, budiana penindra@yahoo.com
}

doi: https://doi.org/10.24843/METTEK.2019.v05.i01.p06

\begin{abstract}
Abstrak
Penelitian kinerja PLTD dual-fuel berbahan bakar solar dan gas hasil gasifikasi bambu di PT. Indonesia Power UBP Bali ini bertujuan untuk mengetahui kemampuan bambu agar mampu mengurangi penggunaan bahan bakar solar yang kini ketersediaannya semakin menispis dengan menggunakan sistem dual-fuel pada pembangkit listrik tenaga diesel. Pengukuran dilakukan dengan mengukur laju alir udara pembakaran dengan bukaan 0\%, 50\% dan 100\%, laju alir gas produser (syngas), konsumsi bahan bakar spesifik, dan daya genset, serta rasio beban listrik yang diberikan $0 \%, 10 \%, 20 \%, 30 \%, 40 \%, 50 \%, 60 \%, 70 \%, 80 \%, 90 \%, 100 \%$ dengan kapasitas genset $40 \mathrm{~kW}$. Data yang didapatkan menunjukkan daya yang dihasilkan dari mode dual-fuel lebih besar yaitu $36,6 \mathrm{~kW}$, dan konsumsi bahan bakar yang lebih sedikit yaitu $6,55 \mathrm{~L} / \mathrm{jam}$ dengan $100 \%$ bukaan valve udara pembakaran.Substitusi penggunaan bahan bakar syngas terhadap bahan bakar solar mampu mengurangi total penggunaan bahan bakar solar sebesar 47,3\% .
\end{abstract}

Kata Kunci: Syngas, Dual-fuel, PLTD, Biomassa Bambu.

\begin{abstract}
Research on the performance of dual-fuel diesel power plant with diesel fuel and bamboo gasification gas in PT. Indonesia Power UBP Bali aims to determine the ability of bamboo to be able to reduce the use of diesel fuel which is now the availability is running low, by using a dual-fuel system in a diesel power plant. Measurements were made by measuring the combustion air flow with openings of 0\%, $50 \%$ and $100 \%$, producer gas flow rate (syngas), specific fuel consumption, and generator power, and the ratio of electrical loads given 0\%, 10\%, 20\%, 30\%, 40\%, $50 \%, 60 \%, 70 \%, 80 \%, 90 \%, 100 \%$, with a generator capacity of $40 \mathrm{~kW}$. The data obtained shows that the power produced from the dual-fuel mode is greater at 36.6 $\mathrm{kW}$, and less fuel consumption of $6.55 \mathrm{~L} / \mathrm{h}$ with $100 \%$ combustion air valve openings.The substitution for the use of syngas fuel for diesel fuel is able to reduce the total use of diesel fuel by $47.3 \%$.
\end{abstract}

Keywords: Syngas, Dual-fuel, Diesel Power Plant, Bamboo Biomass.

\footnotetext{
"Penulis korespondensi,

Email : kputra431@gmail.com@gmail.com,
} 


\section{PENDAHULUAN}

Indonesia adalah Negara berkepulauan terbesar di dunia yang memiliki keindahan dan kekayaan alam yang sangat melimpah. Dalam hal energi, tidak lah mudah untuk mengelola seluruh pulau-pulau tersebut terutama pulau-pulau terpencil. Dengan permasalahan tersebut diharapkan penggunaan PLTD akan sangat bermanfaat menjadi sumber energi listrik. Akan tetapi, seiring berkembangnya jaman ketersediaan bahan bakar fosil (solar) yang digunakan sebagai bahan bakar PLTD semakin hari semakin menipis.

Energi biomassa adalah sumber energi alternatif yang sangat potensial di Indonesia. Biomassa berasal dari tumbuhan. Kekayaan vegetasi yang dimiliki Indonesia meliputi di bidang kehutanan, pertanian, dan perkebunan menyebabkan melimpahnya sumber energi biomassa, baik berbentuk bahan baku ataupun limbah. Salah satu tumbuhan yang potensial yaitu bambu.

PT. Indonesia Power Unit Bisnis Pembangkitan Bali mengembangkan pembangkit PLTD yang bekerja menggunakan dua bahan bakar (dual fuel), yakni minyak solar dan gas hasil gasifikasi biomassa. Karena masih dalam tahap pengembangan, maka diperlukan penelitian intensif terkait daya yang dihasilkan dari dual-fuel tersebut.

Bambu merupakan salah satu tumbuhan yang paling banyak ditemukan di Indonesia. Hampir di seluruh daerah di Indonesia terdapat bambu. Karena melimpahnya ketersediaan bambu dan nilai kalor yang dimiliki berkisar 4005,84-4327,30 kkal/kg, maka sangat cocok untuk menggunakan bambu sebagai bahan baku biomassa terutama untuk daerah kepulauan yang kesulitan dalam listrik tetapi memiliki sumber daya alam berupa bambu atau limbah bambu yang mencukupi.

\section{METODE}

Pengambilan data dilakukan dengan melakukan pengujian pada mesin diesel dalam mode single-fuel yang dimana hanya menggunakan bahan bakar solar pada saat beroperasi dengan bukaan valve inlet udara pembakaran $100 \%$. Data yang didapat pada mode single-fuel adalah daya yang dihasilkan, laju alir udara pembakaran, dan konsumsi bahan bakar spesifik. Setelah melakukan pengujian pada mesin diesel dengan mode single-fuel, dilanjutkan melakukan pengujian pada mode dual-fuel dengan bukaan valve inlet udara pembakaran 0\%, 50\%, dan $100 \%$ yang menghasilkan data laju alir udara gas produser (syngas), daya genset, dan konsumsi bahan bakar spesifik. Pada setiap mode pengujian dipengaruhi dengan pemberian beban listrik 0\%, 10\%, 20\%, 30\%, 40\%, 50\%, 60\%, 70\%, 80\%, 90\%, 100\%. Sehingga dapat diperoleh perbandingan performance dari mode single-fuel dengan mode dual-fuel.

\section{HASIL DAN PEMBAHASAN}

Hasil pengujian kinerja mesin diesel single-fuel di PT. Indonesia Power UBP Bali mendapatkan data laju alir gas produser, konsumsi bahan bakar spesifik solar dan biomassa bambu, dan daya output mesin diesel dengan bukaan $0 \%, 50 \%$, dan $100 \%$ valve inlet udara pembakaran. Data hasil pengujian tersebut dapat dilihat pada grafik perbandingan dan grafik hubungan di bawah ini: 
Jurnal METTEK Volume 5 No 1 (2019) pp 45 - 51

ojs.unud.ac.id/index.php/mettek

ISSN 2502-3829

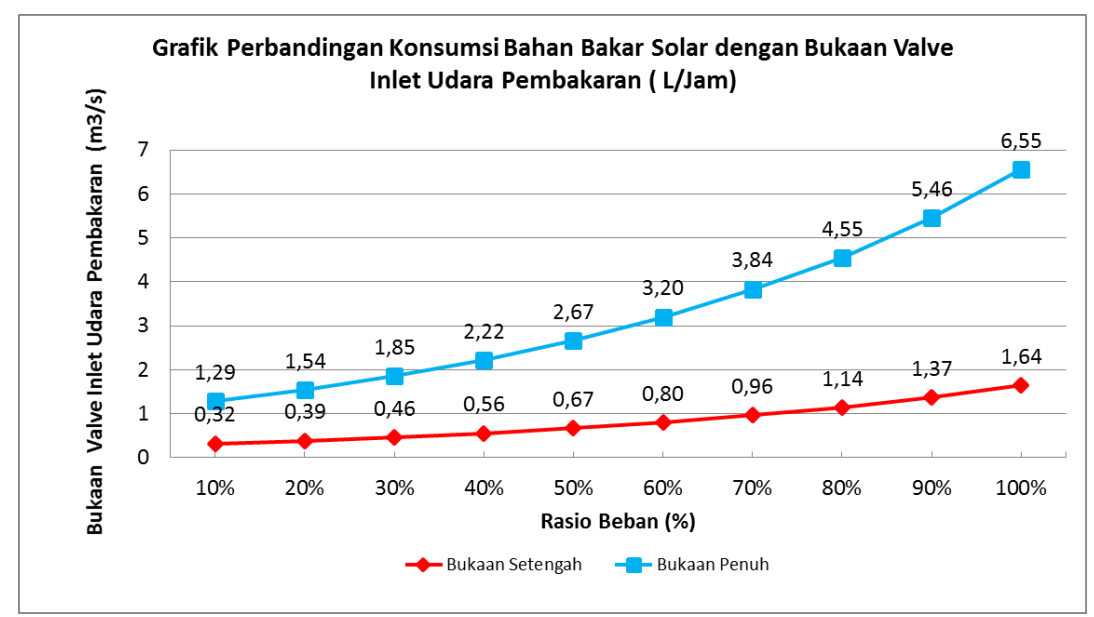

Gambar 1.Grafik perbandingan konsumsi bahan bakar solar dengan bukaan valve inlet udara pembakaran

$$
\text { Konsumsi solar }=\text { berat awal }- \text { berat akhir }
$$

$$
\begin{aligned}
& \begin{array}{l}
\text { 1. Konsumsi solar }=17,621-17,442=0,179 \frac{\mathrm{kg}}{10 \mathrm{~m}} \\
\text { 2. Konsumsi solar }=17,410-17,213=0,197 \frac{\mathrm{kg}}{10 \mathrm{~m}}
\end{array} \\
& \text { Konsumsirata }- \text { rata }=\frac{0,179-0,197}{2} \times 6=\frac{0,376}{2} \times 6=0,188 \frac{\mathrm{kg}}{10 \mathrm{~m}} \times 6=1,13 \frac{\mathrm{kg}}{\mathrm{h}} \\
& \text { Konversi ke liter }=1,13: 0,878=1,29 \frac{l}{\mathrm{~h}}
\end{aligned}
$$

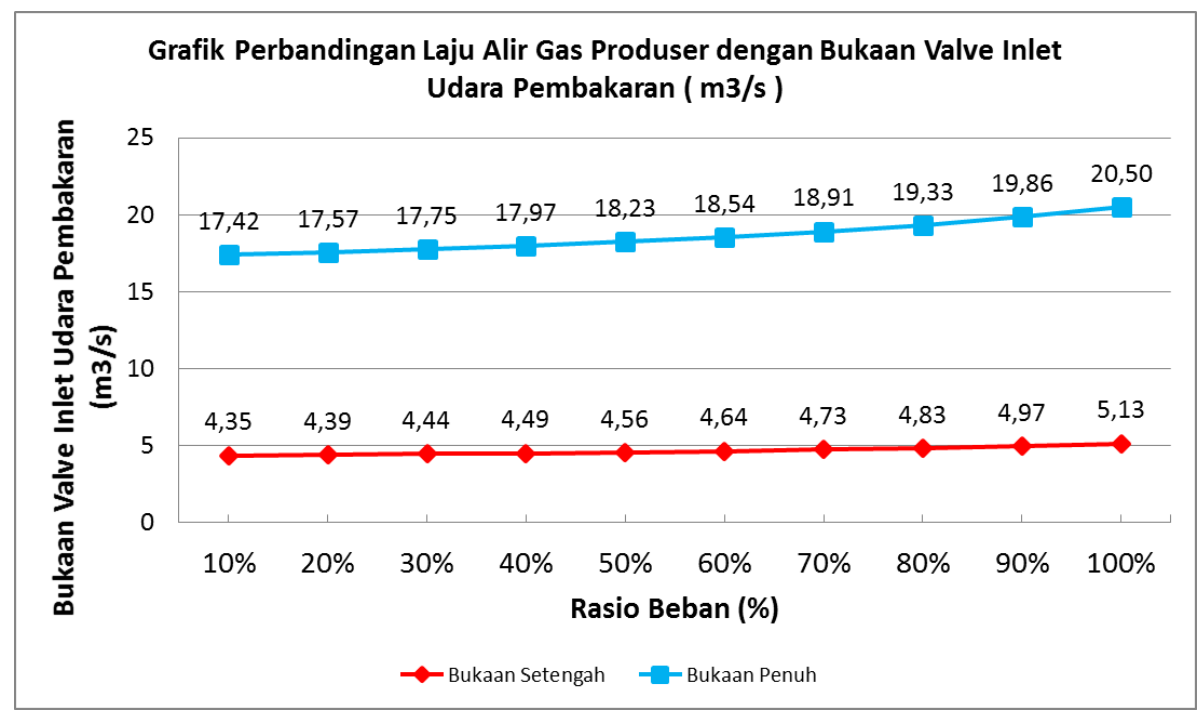

Gambar 2.Grafik perbandingan laju alir gas produser dengan bukaan valve inlet udara pembakaran

$$
\begin{aligned}
& \dot{m}=\rho \cdot v \cdot A \\
& \rho=1,2 \mathrm{~m}^{3} / \mathrm{s}
\end{aligned}
$$




$$
\begin{aligned}
\mathrm{v} & =\frac{\mathrm{m}}{s}=\frac{2 \cdot 11}{0,28}=7,4 \frac{\mathrm{m}}{\mathrm{s}} \\
\mathrm{A} & =\pi \cdot \mathrm{r}^{2}=3 \cdot 14 \times 0,0125^{2} \mathrm{~m}=0,00049 \mathrm{~m}^{2} \\
\dot{m} & =1,2 \frac{\mathrm{m} 3}{s} \cdot 7,4 \frac{\mathrm{m}}{s} \cdot 0,00049 \mathrm{~m}^{2} \\
& =4,35 \times 10^{3} \mathrm{~m}^{3} / \mathrm{s}
\end{aligned}
$$

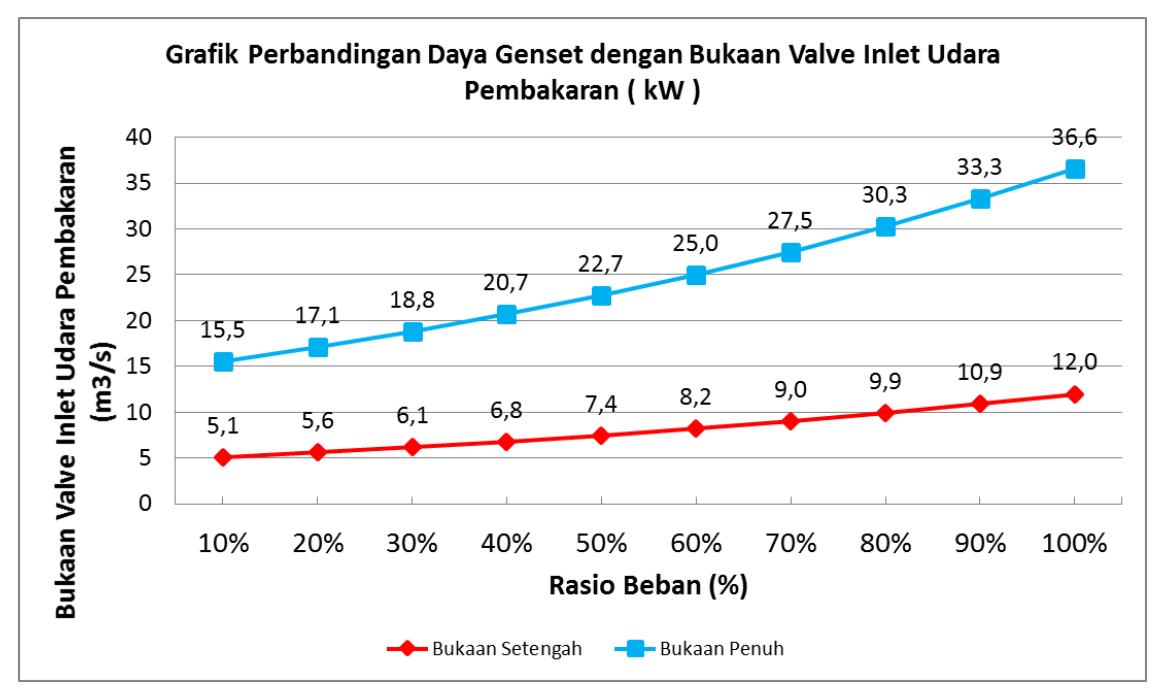

Gambar 3. Grafik perbandingan daya genset dengan bukaan valve inlet udara pembakaran

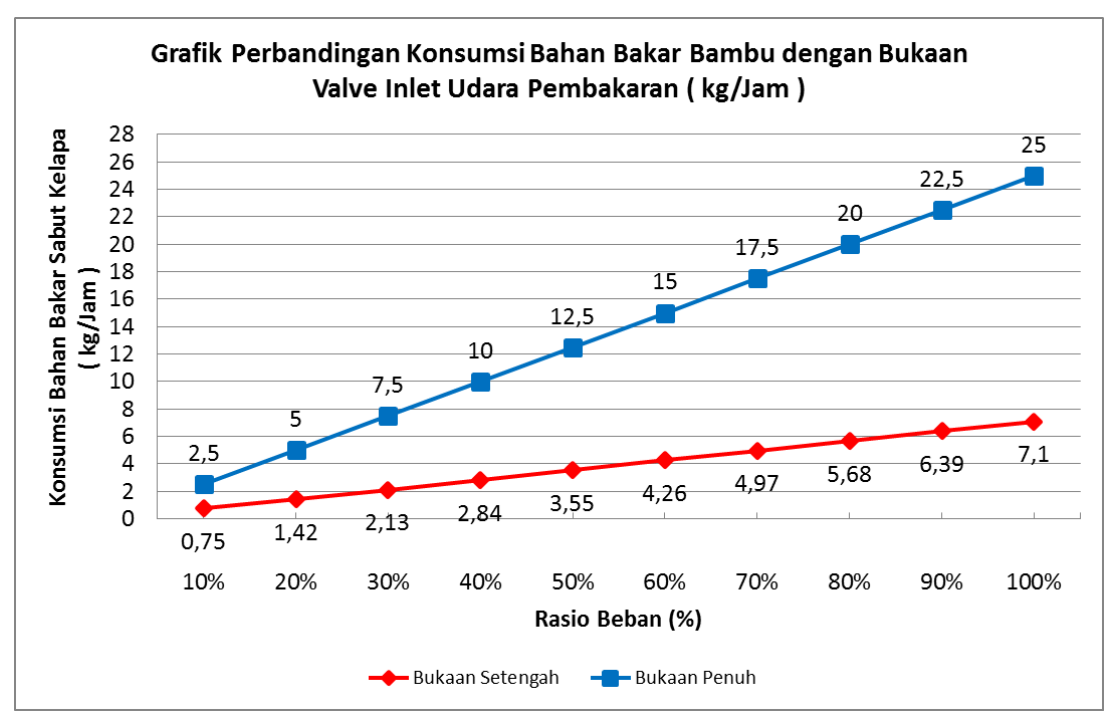

Gambar 4. Grafik perbandingan konsumsi bakar biomassa bambu dengan bukaan valve inlet udara pembakaran

Berdasarkan grafik perbandingan di atas, dapat dilihat bahwa konsumsi biomasa bambu akan meningkat seiring dengan penambahan rasio beban yang diberikan. Konsumsi terbanyak terletak pada bukaan penuh valve inlet udara pembakaran 
dibandingkan dengan bukaan setengah valve inlet udara pembakaran. Untuk memperoleh data konsumsi bahan bakar biomasa bambu dapat digunakan persamaan sebagai berikut:

$$
\text { Konsumsi biomassa }=\frac{\text { biomassa yang digunakan }(\mathrm{kg})}{\text { operasi Genset }(\text { menit })}
$$

- Perhitungan saat Bukaan Setengah:

$$
\text { Konsumsi biomassa }=\frac{25(\mathrm{~kg})}{211(\text { menit })}=0,118 \frac{\mathrm{kg}}{\text { menit }}=7,1 \frac{\mathrm{kg}}{\mathrm{jam}}
$$

- Perhitungan saat Bukaan Penuh

$$
\text { Konsumsi biomassa }=\frac{83,5(\mathrm{~kg})}{200 \text { (menit) }}=0,417 \frac{\mathrm{kg}}{\text { menit }}=25 \frac{\mathrm{kg}}{\mathrm{jam}}
$$

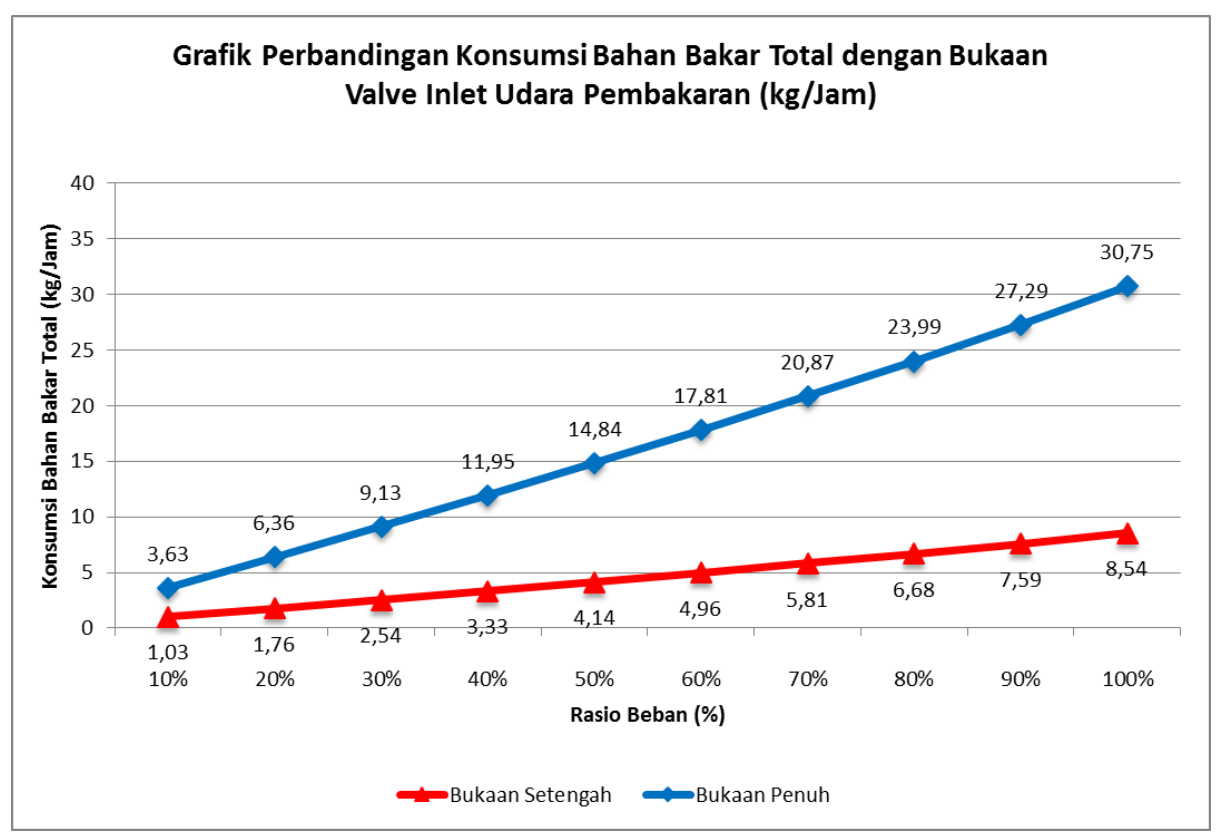

Gambar 5. Perbandingan konsumsi bahan bakar total dengan bukaan valve inlet udara pembakaran

Pada gambar 5 menunjukkan bahwa selisih konsumsi bahan bakar total antara bukaan penuh dengan bukaan setengah valve inlet udara pembakaran adalah 118,79 $\mathrm{kg} / \mathrm{jam}$ yang dimana untuk mendapatkan data konsumsi bahan bakar total dapat digunakan persamaan sebagai berikut:

$$
\text { Konsumsi BB total }=\text { konsumsi solar }(\mathrm{kg})+\text { konsumsi biomasa }(\mathrm{kg})
$$

- Contoh perhitungan bukaan setengah valve inlet udara pembakaran pada rasio beban $10 \%$ :

Konsumsi BB total $=0,282(\mathrm{~kg})+0,75(\mathrm{~kg})=1,03 \mathrm{~kg} / \mathrm{jam}$ 
- Contoh perhitungan bukaan penuh valve inlet udara pembakaran pada rasio beban $10 \%$ :

Konsumsi BB total $=1,130(\mathrm{~kg})+2,5(\mathrm{~kg})=3,63 \mathrm{~kg} / \mathrm{jam}$

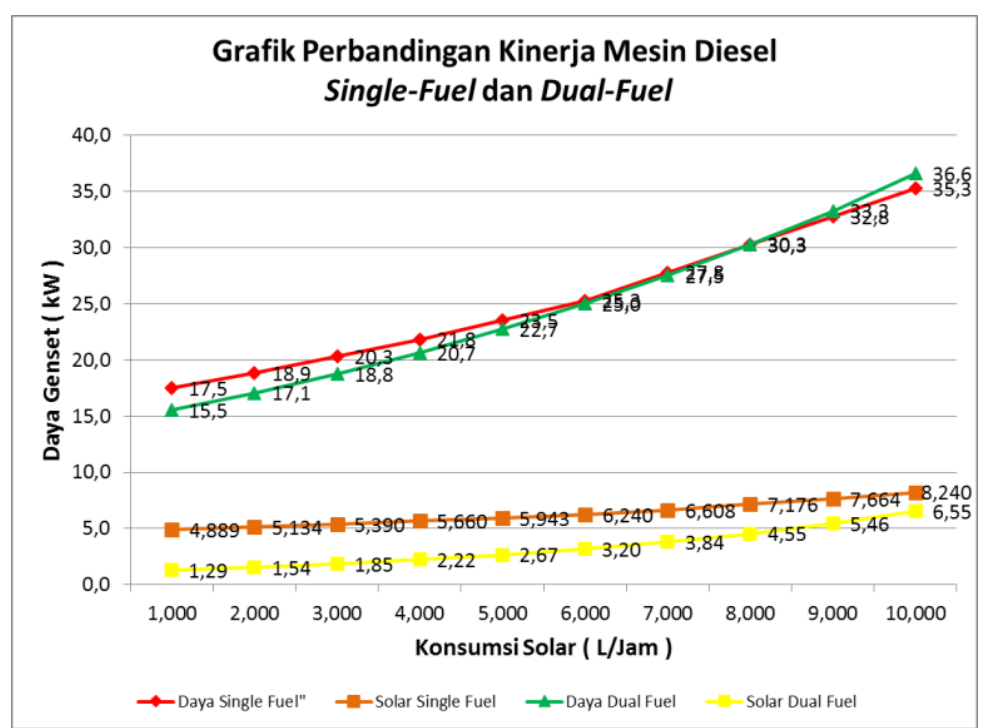

Gambar 6. Grafik perbandingan kinerja mesin diesel single-fuel dan dual-fuel

Pada gambar di atas menunjukkan kinerja mesin diesel dengan mode singlefuel mampu menghasilkan daya output sebesar $35,3 \mathrm{~kW}$ dengan konsumsi dw solar 8,240 1/jam pada bukaan valve inlet udara pembakaran $100 \%$. Sedangkan kinerja pada mesin diesel dengan mode dual-fuel mampu menghasilkan daya output sebesar $36,6 \mathrm{~kW}$ dengan konsumsi solar 6,552 1/jam pada bukaan valve inlet udara pembakaran $100 \%$. Dengan demikian kinerja mesin diesel pada mode dual-fuel mampu menekan penggunaan bahan bakar solar sebanyak 1,688 1/jam dan mampu menghasilkan daya output yang lebih besar yaitu $36,6 \mathrm{~kW}$ sedangkan pada single-fuel yaitu 35,3 kW.

Dari data grafik diatas dapat diperoleh persentase substitusi gas hasil gasifikasi biomassa bambu terhadap bahan bakar solar, sebagai berikut:

Subtsitusi BB Syngas $=\frac{B B_{t} \text { single fuel }-B B_{t} \text { dual fual }}{B B_{t} \text { single fual }} \times 100 \%$

Substitusi bb syngas $=\frac{62,944-33,17}{62,944} \times 100 \%=47,3 \%$ 


\section{SIMPULAN}

Gas hasil gasifikasi biomassa bambu yang digunakan pada mesin diesel dengan mode dual-fuel mampu menekan penggunaan bahan bakar solar sebanyak 1,688 1/jam dan mampu menghasilkan daya output sebesar $36,6 \mathrm{~kW}$ yang dimana $1,3 \mathrm{~kW}$ lebih besar dari daya output mesin diesel pada mode single-fuel. Untuk substitusi penggunaan bahan bakar syngas terhadap solar mampu mengurangi total penggunaan bahan bakar solar sebesar 47,3\%.

\section{DAFTAR PUSTAKA}

[1] [Arhamsyah, 2010. Pemanfaatan Biomassa Kayu Sebagai Sumber Energi Terbarukan. Jurnal Riset Industri Hasil Hutan, Volume 2, Nomor 1, Halaman 42-48.

[2] D Pakiti et al, 2016. Analisis Konsumsi Bahan Bakar Pembangkit Listrik Tenaga Diesel Dengan Substitusi Gasifikasi Sabut Kelapa.

[3] Firman M dan Sihaloho R, 2018. Perancangan Pembangkit Listrik Tenaga Biomassa Berbahan Bakar Bambu Kapasitas 700kW Di Kepulauan X. Seminar Nasional Teknologi 2018, P-ISSN: 2615-1561, E-ISSN: 2615-1553.

[4] Zainuddin $M$ et al, 2017. Analisis Efisiensi Gasifikasi Pada Pembangkit Listrik Tenaga Biomassa (PLTBM) Tongkol Jagung Kapasitas 500 KW Di Kabupaten Gorontalo. Jurnal Sains, Teknologi dan Industri, Volume 14, Nomor 2, Halaman 192 198.

[5] Susanto H, 2010, "Sekilas Tentang Teknologi Gasifikasi", http://esptk.fti.itb.ac.id/herri/index.html. (13 September 2018).

[6] Suliono et al, 2017. Studi Karakteristik Reaktor Gasifikasi Type Downdraft Serbuk Kayu Dengan Variasi Equivalensi Ratio. Jurnal Teknologi Terapan, Volume 3, Nomor 2, ISSN 2477-3506.

[7] Hidayat A, 2014. Karakterisasi Proses Gasifikasi Biomassa Pada Reaktor Downdraft Sistem Batch Dengan Variasi Air Fuel Ratio (AFR) Dan Ukuran Biomassa.

[8] Najib L danDarsopuspito S, 2012. Karakterisasi Proses Gasifikasi Biomassa Tempurung Kelapa Sistem Downdraft Kontinyu Dengan Variasi Perbandingan UdaraBahan Bakar (AFR) Dan Ukuran Biomassa. JurnalTeknik ITS, Volume 1, Nomor 1, ISSN: 2301-9271

[9] Rizkal A danSudarmanta B, 2016. Karakterisasi Unjuk Kerja Diesel Engine Generator Set Sistem Dual Fuel Solar-Syngas Hasil Gasifikasi Briket Municipal Solid Waste (MSW) Secara Langsung. Jurnal Teknik ITS, Volume 5, Nomor 2, ISSN: 2337-3539 (2301-9271 Print).

[10] Subroto, 2017. Kinerja Tungku Gasifikasi Downdraft Continue Bahan Bakar Sekam Padi. Jurnal Ilmiah Teknik Mesin, Volume 18, Nomor 1, Halaman 24-33.

[11] Suyitno, 2009. Energi Dari Biomassa: Potensi, Teknologi, Strategi. Seminar Nasional EnergiTerbarukan Di FMIPA UNS, Surakarta. 